CIC. Cuadernos de Información y Comunicación

ISSN: 1135-7991

\title{
Nueva Comunicología Latinoamericana y Giro Decolonial. Continuidades y rupturas
}

\author{
Francisco Sierra-Caballero $^{1}$; Claudio Maldonado ${ }^{2}$; Carlos del Valle ${ }^{3}$
}

Enviado: 09 de marzo 2020 / Aceptado: 31 de marzo 2020

Resumen. El presente artículo propone avanzar en la configuración de una nueva Comunicología Latinoamericana a partir del relevamiento de la teoría crítica de la mediación social, el encuentro con la cultura académica emancipadora y antagonista de la Escuela Latinoamericana de Comunicación (ELA$\mathrm{COM}$ ) y los fundamentos que ofrece el Giro Decolonial para repensar la Economía Política del Conocimiento. La apuesta por la decolonialidad del saber-poder informativo plantea el reto de reformular las bases del paradigma dominante de la ciencia comunicacional por medio de un "diálogo de saberes" con las matrices culturales y epistémicas que hoy emergen desde el paradigma amerindio.

Palabras clave: Comunicología latinoamericana; ELACOM; Giro Decolonial; Economía Política del Conocimiento; Paradigma Amerindio.

\section{[en] New Latin American Communicology and Decolonial Giro. Continuities and ruptures}

\begin{abstract}
The present article proposes to advance in the configuration of a new Latin American Communicology from the survey of the critical theory of social mediation, the encounter with the emancipatory and antagonistic academic culture of the Latin American School of Communication (ELACOM) and the fundamentals offered by the Decolonial Giro to rethink the Political Economy of Knowledge. The bet on the decoloniality of knowledge-informative power poses the challenge of reformulating the bases of the dominant paradigm of communicational science by means of a "dialogue of knowledge" with the cultural and epistemic matrices that today emerge from the Amerindian paradigm.
\end{abstract}

Keyword: Latin American communicology; ELACOM; Giro Decolonial; Political Economy of Knowledge; Amerindian Paradigm.

Sumario: 1. Introducción. 2. Estado del arte. 3. Comunicología y cambio de paradigmas. 4. Colonialidad epistémica y campo comunicacional. 5. Nuevas cartografías culturales. El problema del Ethos Barroco. 5.1. La comunicación como bien común. 5.2. Comunicación como mediación solidaria. 5.3. La diversidad. 5.4. Escucha activa. 6. Conclusiones. 7. Bibliografía.

[๑ORCID] [GSS] Catedrático de Teoría de la Comunicación. Universidad de Sevilla, US, España.

E-mail: fsierra@us.es

2 Profesor Asistente Universidad Católica de Temuco, Chile.

E-mail: cmaldonado@uct.cl

3 Profesor Titular de la Universidad de La Frontera, Chile.

E-mail: carlos.delvalle@ufrontera.cl 
Cómo citar: Sierra-Caballero, F.; Maldonado, C.; del Vall, C. (2020). Nueva Comunicología Latinoamericana y Giro Decolonial. Continuidades y rupturas, en CIC. Cuadernos de Información y Comunicación 25, 225-242.

\section{Introducción}

Repensar la construcción del campo comunicacional en un escenario de debilidad del pensamiento crítico, pero, a la vez, de emergencia de un ser y pensar "Otro", se presenta como un problema complejo, difícil de acometer en un momento de transición y crisis de paradigmas. Conscientes del potencial de las lógicas sociales que se vislumbran a corto y medio plazo en el horizonte cognitivo de América Latina, donde, como diría Luckács, se observa una nueva conciencia posible, hoy resulta factible definir una suerte de Comunicología del Sur desde Latinoamérica, resultado de los nuevos procesos y luchas que han germinado en el subcontinente y de renovadas ideas que dan cuenta de lugares de enunciación que reivindican lo local y experiencias de intervención social que aportan líneas de desarrollo para la constitución de un innovador pensamiento teórico en la región.

Lo anterior exige reformular las bases epistémicas de la Comunicología en virtud de un proyecto histórico transmoderno, transoccidental, dialógico y articulado desde el Sur, en sintonía a las Epistemologías del Sur. Ciertamente, la apuesta por formas diferentes de ver el mundo, de interpretar e intervenir en él constituye una tradición epistémica propia del pensamiento latinoamericano, construyendo nuevas bases y estilos de conocer y representar el universo a partir de formas comunitarias inspiradas en la filosofía de la liberación y la cultura de la resistencia, las que hoy requieren ser enriquecidas por la emergencia de los movimientos indígenas.

América Latina constituye un territorio de grandes simbiosis y colonizaciones, de migraciones y mestizajes, definiendo un marco socio-histórico conflictivo y liberador. Como reconoce Peter Burke, "América Latina es la región híbrida par excellen$c e$, siendo un lugar de encuentros, choques, mestizajes y todo tipo de interacciones entre la población autóctona, los invasores europeos y los esclavos africanos que llevaron los europeos" (2010:65). El sincretismo que ha marcado las historias locales del subcontinente da cuenta de un potencial insuficientemente explorado por la teoría y la investigación en comunicación a la hora de tratar de comprender la confluencia y cruces de culturas originarias y migrantes, la producción de múltiples mediaciones e hibridaciones creativas, en el origen de otra modernidad posible, proyectada como transmodernidad (Dussel, 2004) $)^{4}$.

Considerando estos aspectos, el presente artículo se propone una discusión que contribuya a la formulación de una nueva Comunicología Latinoamericana, la cual releva la cultura académica emancipadora y antagonista de la Escuela Latinoamericana de Comunicación (ELACOM) a partir de una nueva Economía Política del

Para Dussel (2004), la transmodernidad emerge desde la exterioridad, desde aquellos sujetos que constituyen la diferencia colonial subalterna. Y, a diferencia del proyecto habermaseano que busca completar el proyecto de la modernidad eurocentrada, la transmodernidad se fundamenta en los proyectos descolonizadores que a lo largo de la historia han sido negados como fuentes legitimas de construcción social, política, económica, epistémica, entre otras. 
Conocimiento, fundada en la crítica epistémica del Giro Decolonial. La apuesta por la decolonialidad del saber-poder informativo plantea el reto de reformular el paradigma dominante de la comunicación occidental a partir de un "diálogo de saberes" con matrices culturales y epistémicas del paradigma amerindio.

\section{Estado del arte}

La ELACOM surge como propuesta autónoma de investigación en el marco desarrollista de la modernización acelerada en el que estaba inmersa América Latina. El "atraso" tecnológico y social, visto desde la concepción del progreso y el desarrollo de la modernidad, llevaron a pensar la investigación hacia el modelo difusionista que "contenía una serie de supuestos sobre el subdesarrollo, el desarrollo y la relación entre comunicación y modernización" (Catalán \& Sunkel, 1991:5). Estas primeras investigaciones se inscriben en el denominado paradigma funcionalista, cuya visión sobre la modernidad en Latinoamérica estará guiada por la hipótesis de la carencia. Por otro lado, la incursión dentro de la Teoría Crítica de la Escuela de Frankfurt, a partir de los trabajos de Pasquali, fueron fraguando una mirada más política, que entiende a la comunicación como un instrumento ideológico. Por el lado de los estudios funcionalistas la tendencia es al desarrollismo, mientras que desde la Teoría Crítica, y luego la semiología, la tendencia es a cuestionar y poner en entredicho tal desarro1lo. Esta perspectiva también se realizó en función de una práctica política y procesos de mudanza de gran originalidad e interesantes para el avance del conocimiento comunicacional (Catalán \& Sunkel, 1991). Pues, entre otros procesos, ello contribuyó a una hibridación epistemológica, como origen de la llamada Escuela Latinoamericana de Comunicación (Marques de Melo/Gobbi, 2003).

Definimos Escuela Latinoamericana de la Comunicación (ELACOM) al corpus de análisis de la comunicación y la cultura, con elementos epistémicos y metodológicos diferentes a los desarrollados en los ámbitos de la academia de Europa y Estados Unidos, en virtud de una hibridación teórico-metodológica original que atiende a la especificidad histórica y la emergencia de sincretismos y nuevas lógicas de modernización marcada por la pluralidad de las culturas populares massmediatizadas. Tal reconocimiento participó de una práctica teórica surgida como ruptura y desconstrucción frente a las corrientes de pensamiento dominantes procedentes de los centros metropolitanos occidentales, es decir, frente a las teorías foráneas del funcionalismo norteamericano y la teoría crítica marxista de la Escuela de Frankfurt; al mismo tiempo que se enunciaban nuevas agendas propias adaptadas al contexto de movimientos y luchas políticas y sociales de la región, construidas desde la dialéctica de la hibridación y el mestizaje que reconoce la praxis, la diversidad y la participación como medulares en la comunicación, entendida como mediación social (Herrera, Sierra, Del Valle, 2016).

El reconocimiento de las particularidades históricas y culturales de América Latina permite comenzar a tejer la propuesta de comprensión de la comunicación desde la perspectiva social y cultural, superando los reduccionismos mediocéntricos e informacionista dominantes hasta entonces (Martín-Barbero, 2010). Ambas tendencias, la social y la cultural, marcarán el desarrollo de la investigación en América Latina entre los años 70 y los 90 (Moragas, 2011) 
El redescubrimiento de lo propio como empoderamiento del pensamiento y la realidad latinoamericana se traduce en la ELACOM en una reivindicación de la diferencia. Pero también en un cuestionamiento y antagonismo de la norma y el pensamiento dominante de la modernización occidental y la ciencia positiva hegemónica del Norte. A su vez, contribuyó a un despliegue teórico donde el reconocimiento de las estructuras microsociales y de las subjetividades comenzó a prevalecer sobre el análisis funcional y las lecturas neopositivistas de la joven Teoría de la Comunicación (Sierra, 2010). A la vez, centros como ILET, CIESPAL, o publicaciones de referencia como Comunicación y Cultura, afirman la pertinencia y necesidad de defender una filosofía de la cooperación Sur-Sur basada en la comunicación como derecho y bien social al servicio del desarrollo comunitario.

\section{Comunicología y cambio de paradigmas}

Boaventura de Sousa Santos (2010a) afirmó que vivimos tiempos de preguntas fuertes y de respuestas débiles. Una crisis civilizatoria y de paradigmas que deriva del cuestionamiento radical de los valores que han regido el sistema dominante de mediación social exportado desde el Norte de Europa, a finales del siglo XV, en forma de filosofía única de la modernidad. Especialmente, en las últimas décadas, nuevos conceptos como la noción andina de Buen Vivir y Vivir Bien dan cuenta de la emergencia de renovadas formas de organización y dinámicas emancipadoras desde el Sur, entendido como una localización no tan sólo geográfica, sino también epistémica e identitaria.

Sabemos que el pensamiento eurocéntrico tiene dificultades de reconocer las formas internas y externas de opresión y desigualdad excluyente, pues tiende a omitir o ignorar las formas hegemónicas de reproducción que lo fundamentan. Tan notoria es la ausencia de una observación situada sobre los regímenes de verdad de la ciencia positiva occidental que es posible afirmar que un problema fundamental de nuestro tiempo es de orden teórico y epistémico, como señalan los estudios decoloniales en América Latina (Lander, 2000). Esto es, necesitamos un principio o efecto $\mathrm{V}$ de distanciamiento, en términos de nueva filosofía de la praxis, si queremos cambiar la ontología de la modernidad, y estar simultáneamente dentro y fuera de lo que se critica, "de tal modo que se torne posible la doble sociología transgresora de las ausencias y las emergencias" (Sousa Santos, 2010b:21). En esta línea, una idea central para la Comunicología es definir "otro saber posible" de la comunicación, empezando por recuperar las tradiciones y alternativas culturales silenciadas o simplemente excluidas por el avance y consolidación del proyecto modernizados de Occidente.

Para lo anterior se requiere abordar las relaciones imperantes en los flujos económicos y la estructura real de la información, el colonialismo ideológico y cultural, así como las formas gubernamentalizadas de ciencia y conocimiento administrativo, lo cual exige una concepción más amplia de la mediación. Desde este punto de vista, la opresión de toda teoría y práctica científica debe ser objeto de cuestionamiento situado. No es posible repensar una nueva Comunicología Latinoamericana si no como Ecología Política de la Comunicación. Ello significa enfrentar: 
- La crítica de la naturaleza imperial de las relaciones sociales y de comunicación, repensando la articulación entre conocimiento, investigación y razón como dominio instrumental.

- La crítica de los protocolos e instituciones de la ciencia occidental, así como los instrumentos y tecnologías de captura de información que fungen, en la actualidad, como dispositivos de legitimación de las prácticas coloniales.

- La crítica y defensa de las normas desde la autonomía y soberanía de las culturas tradicionales presente en la emergencia de los movimientos indígenas.

- Y la escritura de una "historia-otra" a partir de nuevas matrices culturales.

\section{Colonialidad epistémica y campo comunicacional}

Todo trabajo que se proponga problematizar el campo científico debe, obligatoriamente, atender las condiciones socio-históricas que modelan la producción de saberes y la posición que estos asumen dentro de los marcos geopolíticos de regulación y legitimación del conocimiento. Para ello, el análisis de contexto no puede quedar reducido a la contingencia. La lectura a efectuar requiere reconocer en el presente las huellas de un proceso de larga data.

Desde esta perspectiva, se entiende que los rasgos que definen a los estudios comunicacionales en la región latinoamericana obedecen a las coordenadas epistémicas que estructuran el proyecto civilizatorio de la modernidad occidental.

Recogiendo los argumentos del denominado "Giro Decolonial", la modernidad deja de concebirse como un fenómeno intraeuropeo, anclado a los procesos de secularización que desde el siglo XVII y XVIII dieron paso a la etapa de la Ilustración. Para Dussel (1994, 2011), Mignolo (2003), Quijano (1992, 2007) y Quijano y Wallerstein (1992), la modernidad tiene su génesis en la conquista y colonización de América Latina, re-lectura que modifica no sólo las coordenadas temporales de su fundación, pues deja en evidencia que este proyecto civilizatorio se sustenta en un aparato de dominación estructural que hoy conceptualizamos como "colonialidad".

La colonialidad refiere a un sistema de clasificación social de las poblaciones que posibilita el control de diversos ámbitos de la existencia humana:

(1) el trabajo y sus productos; (2) en dependencia del anterior, la "naturaleza" y sus recursos de producción; (3) el sexo, sus productos y la reproducción de la especie; (4) la subjetividad y sus productos materiales e intersubjetivos, incluido el conocimiento; (5) la autoridad y sus instrumentos, de coerción en particular, para asegurar la reproducción de ese patrón de relaciones sociales y regular sus cambios. (Quijano, 2007, p.96)

La colonialidad es un dispositivo de poder que opera en términos de "heterarquía" (Kontopoulus, 1993), estableciendo conectividades polimórficas entre niveles diferenciados que van desde lo material y estructural a lo simbólico y subjetivo. Ello permite comprender que la colonialidad se ejerce imbricando dimensiones heterogéneas (raza, clase, género, etc.), concepción que supera las lecturas deterministas y jerárquicas en torno al modus operandi del poder. 
Ahora bien, para los fines de este trabajo, nos detendremos en una de las aristas específicas de la colonialidad, desde la premisa que ésta no puede ser disociada de la matriz colonial que rige los modelos de clasificación y control de las poblaciones a nivel estructural. En efecto, la "colonialidad del saber" que experimenta el campo comunicacional está intersectada otras formas de dominio, las cuales se despliegan en la totalidad del sistema mundo moderno-colonial. No obstante aquello, por cuestiones operativas, nos detendremos a problematizar únicamente la exclusión cognoscitiva impuesta por la modernidad/colonialidad.

Siguiendo la perspectiva de Habermas, el proyecto de la modernidad "formulado por los filósofos del siglo XVIII" contó con la creación de una ciencia objetiva que se propuso liberar "el potencial cognitivo" de toda forma de saber "esotérico", para así emplear esta cultura especializada en el "enriquecimiento de la vida diaria, es decir en la organización racional de la cotidianeidad social" (1993:137-138). Pero lo que omite Habermas en sus reflexiones es que tres siglos antes este proyecto racionalista estuvo condicionado por la exclusión y dominación de diversas poblaciones, cuyos saberes fueron desplazados hacia los márgenes del régimen epistémico que la modernidad/colonialidad comenzaba a diseñar a partir del nacimiento del ego conquiro, antecesor del ego cogito cartesiano (Dussel, 2011). ${ }^{5}$ En tales términos, la racionalidad moderna presentada como el fundamento de la libertad humana, pasa a ser concebida como una racionalidad fundada en la dominación y el control de la diferencia. Santos (2010a) al referirse sobre las condiciones de producción de conocimiento en contextos marcados por el colonialismo, enfatiza que en estos se configura un "pensamiento abismal" 6 , el cual genera la fragmentación entre lo humano y lo subhumano, puesto que lo que se pone en duda no es tan solo la validez de los saberes del otro-colonizado, sino su propia condición de ser-humano. ${ }^{7}$

La permanencia de este modelo distributivo del saber ha perdurado durante siglos, evidenciándose en los cuestionamientos que hoy siguen manifestándose en torno a la legitimidad de aquellos sistemas cognitivos que no responden al método de la racionalidad moderna, tal es el caso de la desvalorización de los saberes indígenas, los cuales, adicionalmente, han sido objetualizados para servir como mero material de investigación, dando cuenta de un "extractivismo epistémico" (Grosfoguel, 2016) que hace que los procesos de investigación científica sean asumidos por las comunidades como prácticas colonialistas (Tuhiwai, 2016).

Enrique Dussel (2011) establece que el ego cogito de la modernidad Ilustrada está antecedido por el ego conquiro de la colonización, para así dar cuenta que la modernidad se sustenta en una "no-ética de la dominación”. Es por ello, además, que Dussel (2002) plantea la idea de una Primera Modernidad, la cual emerge conjuntamente con el nacimiento del ego conquiro, poblaciones que habitaban lo que hoy es Latinoamérica. Esta primera modernidad, para Dussel, desmantela los mitos que sostienen a la segunda modernidad, entendida como aquella que se sustenta en los ideales del razonamiento ilustrado, la libertad e igualdad y fraternidad entre los hombres. Antagónicamente, la primera modernidad da cuenta que ese relato omite los procesos de explotación, mortandad, exclusión y deslegitimación que dieron origen a la Modernidad en su relación con los otros a dominar.

6 Boaventura de Sousa Santos (2010a) utiliza el concepto de pensamiento abismal para aludir a los sistemas de clasificación de saberes que han operado en contextos coloniales, los cuales se basan en la deslegitimación de todo complejo epistémico que no se adapte al canon de la racionalidad del occidente global. Dicho sistema de clasificación, a nuestro modo de ver, sigue operando en la era actual a través de una geopolítica del conocimiento que prioriza las agendas investigativas del Norte-Global.

7 Fanon (2001) señaló con claridad que toda política colonial apunta al diseño de un "mundo cortado en dos", dividiendo el mundo entre el reino de lo humano (colonial) y lo no humano (colonizado). 
Lo anterior trasciende al plano de la estratificación geopolítica del conocimiento, marco de análisis que como bien explica Vercellone (2004) debe ser confrontado en directa relación a las mutaciones que ha experimentado el capitalismo, pasando desde su fase industrial al actual "Capitalismo Cognitivo".

Las reglas generales de la producción y validación del conocimiento reproducen, sistemáticamente, regímenes epistémicos coloniales y capitalistas. En este mismo sentido, Wallerstein (2007) plantea su crítica al universalismo pan-europeo, el cual se ha manifestado, al menos, en tres estrategias: 1) la distinción civilización/barbarie 2) el particularismo esencialista y 3 ) el cientificismo universalista.

Es en este marco donde debemos situar la emergencia del campo comunicacional en Latinoamérica, como proyecto autónomo, diferenciado y decolonizado.

Decolonizar el campo de la comunicación implica transparentar y reconstruir la historia y memoria de América Latina para generar procesos de producción y valoración de los saberes locales, prácticos, ancestrales y populares que fueron subestimados y subyugados por los saberes universales de las ciencias sociales cuyo "conocimiento es abstracto, desincorporado y deslocalizado" (Walsh, 2005:42). Una descolonización del saber desde la ELACOM, en confluencia con el "Giro Decolonial", implica un ejercicio de heteroglosia, como representación de la coexistencia de lenguajes y voces que se complementan, se cruzan o se contradicen entre sí a partir de una interrelación dialógica (Bakhtin, 1981). En esta línea,

- la apuesta por una decolonización significa un "diálogo de saberes" en tres tendencias:

- la integración entre saberes teóricos y saberes prácticos;

- la necesaria reflexión y acción desde el intercambio entre saberes comunes, cotidianos, populares, ancestrales, artísticos y científicos en el marco de la autodeterminación de los pueblos y las culturas locales;

- la complejidad de la relación entre saberes que provienen de diferentes campos o disciplinas, como parte fundamental de un paradigma emergente en el cual "la superación de la dicotomía ciencias naturales/ciencias sociales, tiende así a revalorizar los estudios humanísticos." (De Sousa Santos, 2009:46)

El reto no partiría de cero. En el campo de la Comunicación el diálogo con la inclusión de saberes populares y ancestrales se ha abierto paso hace décadas con los trabajos de Folkcomunicación iniciados por Luiz Beltrão, en los cuales se comprenden los procesos de la cultura brasilera para percibir los festivales, la literatura, los exvotos, la feria popular, el carnaval, entre otras manifestaciones populares, como un acto de comunicación (Beltrão, 1971, 2004). Otra referencia es la investigación liderada por Luis Ramiro Beltrán, la que pone de manifiesto la necesidad de repensar las formas precolombinas y contemporáneas de la comunicación indígena (Beltrán, Herrera, Pinto, \& Torrico, 2008). A este trabajo le anteceden las publicaciones de

\footnotetext{
Vecellone establece: "El contenido esencial de esta refundación de la acumulación de capital reposa sobre la «captación» de la economía del saber en un medio y en un beneficio financiero y en la generalización de una economía rentista. En este marco, el drenaje formidable de recursos opera del Sur al Norte gracias a los servicios de la deuda, del mismo modo que la extensión del sistema de patentes y la puesta en marcha de un «capitalismo accionarial» operan como elementos del mecanismo de expoliación y de explotación rentista del trabajo de las multitudes."(2004:67).
} 
Leonardo Ferreira (2000) sobre la narrativa y comunicación precolombina y el trabajo de Juan Gargurevich (2002) sobre la comunicación precolombina y de la época de la conquista en Perú, entre otros. No obstante, la producción científica en esta línea sigue siendo escasa, pese a que el tema de la comunicación indígena toma fuerza en las agendas de investigación actual (Magallanes \& Ramos, 2016).

Ahora bien, los investigadores en comunicación de América Latina tienen el desafío de luchar contra la injusticia cognitiva generando nuevas gramáticas de pensamiento mediante el fortalecimiento de redes transfronterizas de producción de conocimiento y prácticas mancomunadas para la circulación desde y entre el Sur. La propuesta apunta al establecimiento de otro tipo de redes, distintas a las establecidas desde las jerarquías indicadas entre el Norte y el Sur, entre lo global y lo local, lo universal y lo específico. "El desafío de esta nueva autonomía reside en construir lazos sur-sur que nos permitan romper los triángulos sin base de la política y la academia del norte" (Rivera, 2006:12). Esto implica una reivindicación de nuestro pensamiento latinoamericano para construir la lógica de nuestro propio capital cultural, que incluye para esta descolonización una política científica basada en la solidaridad académica que permita reconocernos y pensarnos desde los parámetros propios de nuestras vetas culturales e históricas, en una recuperación y reinterpretación de nuestra memoria como continente. Y ello, a partir de una crítica epistemológica a los estudios hoy hegemónicos en los Cultural Studies de la Comunicación Intercultural.

\section{Nuevas cartografías culturales. El problema del Ethos Barroco.}

El problema de la Comunicación Intercultural constituye un analizador histórico determinante para una nueva teoría de la comunicación en América Latina. Y en este proceso, además de reformular desde el giro decolonial la historia y geopolítica del conocimiento, es preciso una interpretación semiótica de la producción y reproducción social adecuada a la era del Capitalismo Cognitivo. En este empeño, los aportes de las tesis sobre Ethos Barroco de Bolívar Echeverría $(1997,2011)$ son del todo pertinentes.

Bolívar se sitúa al pensar la ideología y las políticas de la representación reivindicando la modernidad barroca, fundamento de una "forma-otra" de mediación latinoamericana, a modo de resistencia, contraconquista o adaptación creativa del espíritu protestante del capitalismo. Si analizamos esta tesis definida en "Las ilusiones de la modernidad" (1995), "Valor de uso y utopía" (1998) y "La modernidad de lo barroco" (1998), al hilo de la propuesta del giro decolonial y los rasgos que definen a la ELACOM, podemos reconocer la importancia de la comunicación en el proceso de resistencia y contestación de las lógicas de reproducción ideológica del capitalismo como una dinámica compleja, abierta y contradictoria.

Parte original del debate contemporáneo en ciencias sociales suscitado por los partidarios del llamado paradigma andino-amazónico, o de discusiones en torno a la noción de Comunicación para el Buen Vivir (Restrepo y Valencia, 2017; Contreras, 2016, Maldonado, Reyes y Del Valle, 2015; Barranquero y Sáez, 2014), es justamente la diversidad de interconexiones nómadas, múltiples y dispersas de lo global y lo local, de lo público y lo privado o, en el caso de la obra de Bolívar Echeverría, del valor de uso y la forma natural versus la valorización capitalista que atraviesa todo proceso de dominación ideológica. Esta lectura admite un desarrollo y despliegue 
productivo para la teoría de la comunicación a la hora de pensar la ideología como un proceso instituyente de las dinámicas de reproducción social que conviene abordar, a todos los efectos, desde el mirador productivo de Bolívar. O en otras palabras, la emergencia de una nueva teoría crítica de la mediación pasa en América Latina por hacer visibles los nuevos mecanismos de producción de las diferencias en tiempos de globalización. Y en el caso latinoamericano, ello implica la descolonización del campo académico, desmarcándose de los binarismos analíticos que hoy por hoy no permiten "conceptualizar las nuevas configuraciones del poder" (Castro-Gómez, 2000:159).

Se trataría de definir nuevos mapas y cartografías culturales problematizando la Comunicación Intercultural y las luchas indígenas como analizador de la Economía Política del Conocimiento, de la propia lógica de la hegemonía del pensamiento comunicacional modernizador que coloniza las agendas, sistemas y políticas científicas de nuestros países. Y ello en virtud de una nueva ecología y una visión transversal y contextualizada que apunta la potencia del paradigma amerindio como matriz de un proyecto transmoderno.

Si la transmodernidad es aquello que se sitúa más allá y también antes de las estructuras valoradas por la cultura moderna europeo-norteamericana y que apunta hacia un diálogo intercultural, la necesaria ruptura epistemológica que proponemos con una Epistemología del Sur en Comunicación pasa por acometer cuatro frentes cognitivos:

- Los criterios de relevancia y pertinencia científica en Comunicología.

- La agenda de estudios.

- El reconocimiento de las voces indígenas.

- Los criterios de evaluación e interpretación cultural.

La hipótesis de partida del ethos barroco es el fundamento cultural que puede garantizar en América Latina acometer estos frentes, pues permite una subjetivación política y la emergencia de un nuevo sujeto de conocimiento legitimando el saber-poder como disyunción, subsunción y excentricidad, necesarios como parte de los espacios liminares en la llamada Economía Creativa.

Apostar por ello es dislocar la práctica de representación de la Teoría Global de la Comunicación, del centro angloamericano en favor de los márgenes amenazados, a partir de una fenomenología de la marginalidad basada en el uso creativo de las tradiciones culturales amerindias.

Más allá de las definiciones al uso sobre lo que representa el pensamiento de la liberación en América Latina, lo cierto es que este legado y la práctica científica presupone un proceso de aggiornamento, de una praxis revolucionaria de la investigación al servicio del bien común, la cual no debe obviar los elementos y funciones sustanciales de toda teoría crítica:

- Revelar lo oculto, eludido o enterrado.

- Desplegar los vínculos y relaciones negadas u omitidas.

- Apuntar alternativas de acción y reflexividad dialógica.

- Potenciar los encuentros, mediaciones y articulación de las potencialidades liberadoras. 
Hablamos de pensar una Ecología Política de la Comunicación como nueva formulación fundada en la dialéctica entre tradición y modernidad. Esta nueva ecología deberá atender al menos cinco principios básicos que desarrollamos a continuación, siendo pensados como ejes programáticos a desplegar en la ruptura epistemológica que representa el esfuerzo de configuración de una nueva Comunicología Latinoamericana:

\subsection{La comunicación como bien común}

La palabra "comunicar", en su etimología latina, remite a la noción de lo común. Significa relacionar, concatenar, organizar o dejarse organizar por la dimensión constituyente, intensiva y presubjetiva de ordenamiento simbólico del mundo. Ello remite al lenguaje de los vínculos, a la dimensión transversal o compleja de toda mediación, lo que confirma la necesidad de pensar la Comunicación como un problema de Ecología Cultural o Ecologías de Vida. Se trata de un cambio de paradigma para transformar los modelos de redistribución y producción de la riqueza y del propio ecosistema cultural. En esta tarea, es preciso redefinir las formas habituales de visibilidad "construyendo otras imágenes y formas de rearticulación del espacio público", apostando por redes locales, radicalmente descentralizadas, y comprometidas en procesos globales de democratización y desarrollo social. A partir de los colectivos locales, organizados autónomamente, pero coordinados en red, se trata de maximizar la creatividad cultural y la producción de conocimiento según la regla C3A: COMUNICACIÓN; COLABORACIÓN, COORDINACIÓN Y ACCIÓN SOCIAL SOLIDARIA. Este sería el sentido de la Comunicación, concebida como Ciencia de lo Común.

\subsection{Comunicación como mediación solidaria}

De acuerdo con la noción de Buen Vivir, el cometido de la Comunicación no es otro que la "solidaridad", al tratar de mediar y articular socialmente las necesidades populares. Desde este punto de vista, necesitamos una ampliación simbólica de los saberes, las prácticas y actores comprometidos en la mediación social, reconociendo el principio de complementariedad y el saber-hacer en común, esto es, el principio de religancia y la comunicación de proximidad, pues es el espacio local el lugar de conservación, creación y recreación de las lógicas globales e ingobernables del desarrollo contemporáneo. Volver a los lugares y ecos de la palabra caminante en su territorio de procedencia constituye por lo mismo una apuesta por la racionalidad solidaria, por la idea fraterna de la comunicación como urdimbre, tejido o hábitat de vida en común, un programa de trabajo sobre el clinamen que hace posible y necesaria la palabra compartida.

\subsection{La diversidad}

América Latina es el espacio geopolítico de mayor diversidad y mestizaje en la historia de la humanidad. La región es un ejemplo de criollización, intercambio, colisión, contactos y esperanza de una vida nueva cuya identidad negada es, paradójicamente, fruto de nuevos encuentros con otras raíces en la construcción de 
la diversidad narrativa que nos constituye. Ahora bien, esta biodiversidad ha sido permanentemente cercada. La destrucción del conocimiento de los pueblos originarios es la principal barbarie de la modernización. Esta crítica epistemológica supone pensar una política para el pluriverso, que acepte muchos conocimientos posibles frente al universalismo abstracto de la modernidad (Restrepo \& Rojas, 2010). Históricamente, el dominio científico-técnico occidental se ha traducido en una suerte de epistemicidio y negación de la diversidad de formas de conocimiento y experiencia. El reto de nuestro tiempo, en este sentido, pasa por suturar o romper dichas brechas, definiendo alternativas de/pos-coloniales y antiimperialistas que, por poner un caso, asuma una concepción intercultural de los derechos humanos capaz de establecer una nueva relación de equilibrio dinámico entre el principio de igualdad y el principio de reconocimiento de la diferencia. Se trata de recuperar los saberes y conocimientos populares, la praxis tradicional indígena, campesina y plebeya, el modus vivendi de la economía moral de las multitudes. Un proyecto histórico que reclama de los medios de comunicación un enfoque plural y dinámico, cómplice y dialógico, comprometido y transformador. Y una epistemología de deconstrucción de las tecnologías de la mirada positiva occidental sobre lo otro negado. Ello presupone retos en materia de decolonización intelectual del campo comunicológico, la apertura a otras voces y matrices culturales y nuevas prácticas académicas, capaces de asumir la radicalidad del diálogo, así como la hybris presente en las poéticas y narrativas de los pueblos amerindios. En otras palabras, ello nos emplaza a explorar la potencialidad del Buen Vivir para una reconfiguración de las ecologías culturales y epistémicas. Esta apuesta trasciende el paradigma representacional o lógico-formal propia de la racionalidad cartesiana o positiva, optando por una estética y un pensamiento basado en la narración y la política de la vida. Se trata de observar las tradiciones y comprender las prácticas y rituales renunciando a la concepción de la costumbre como reliquia en una suerte de distanciamiento etnográfico condescendiente. Desde este punto de vista, lo personal, lo informal, lo común e inmaterial, presente en rituales, la comunidad, y dialogía interna a toda cultura, es concebido, en coherencia con en este sentido, como un nuevo universo referencial de prácticas del Buen Vivir, como lo común, bueno y equilibrado. La dialogía presupone la producción de una comunicación crítica respetuosa con la multiplicidad de la conciencia posible, haciendo factible la plenivalencia (la valorización de las voces en igualdad radical en el espacio público) y la equipolencia (la singularidad, autonomía y mismidad no objetivables de dichas voces). Ahora bien, para ello se precisa una cierta política de convergencia, de alianzas y combinaciones, orientando síntesis creativas y desbordantes en la tensión dialéctica de tradición y modernidad. Así como también una política fundada en los principios de una hermenéutica pluritemática, capaz de abrirse y poner en valor las narrativas epistémicas y experienciales de aquellas comunidades subalternizadas por la modernidad/colonialidad (Mignolo, 2003). La ciencia de los intercambios es la condición de toda ecología cultural en la medida que reconcilia lo común. Y ello excluye la visión esencialista de toda matriz cultural que el idealismo modernista fijaba respecto a las culturas indígenas y comunitaristas tradicionales, como también ciertas lecturas pachamámicas prefiguran el ideal indígena como un modelo ajeno a las contaminaciones culturales. La apuesta por la traducción deconstruye la dialéctica monológica de la comunicación. 


\subsection{Escucha activa}

La era del Capitalismo Cognitivo es la era de los prosumidores, el tiempo de las redes distribuidas y participadas de comunicación que hacen posible y necesario el principio rector de toda dialogía: la atenta escucha. La emergencia de figuras como el PROAM (profesional-amateur) de la información o de movimientos como ANONYMOUS en defensa de las libertades públicas son indicativos de un proceso de descentramiento de la función privilegiada que tenían los periodistas en pro de la tradición teórico-metodológica de la Comunicación Participativa. En medio de esta incertidumbre y los cambios acelerados que tienen lugar en las prácticas de consumo y relación del ciudadano digital, sería el momento de repensar, crítica y reflexivamente el horizonte de futuro y la agenda de la Comunicología, comenzando por observar las numerosas iniciativas emergentes que proliferan al margen y rededor de las grandes compañías dominantes en el mercado, interpelando a los intermediarios de la cultura para hacernos recordar que el diálogo es una condición existencial y que, en consecuencia, el futuro del periodismo dependerá de la capacidad a la adaptación creativa a partir de la escucha activa. Se trataría de la voluntad de autonomía, de una política de comunicación fundada en el escuchar, principio rector de una comunicación horizontal (Beltrán, 1981). Del desprendimiento al encubrimiento, aprender a crear hoy no es posible sin empatía ni voluntad de fascinación y admiración. La capacidad de asombro es la forma material de atender al otro y, cognitivamente, el modo habitual para explorar la diferencia con la idea de experimentar otra manera de ver y/o vivir. $Y$ en el sentido originario de saber escuchar como principio rector del vivir bien implica, de acuerdo con Contreras, la participación, la aceptación reivindicativa de la palabra reparadora, la con/vivencia, y, en cierto sentido, el principio maya de mandar obedeciendo (Contreras, 2016).

\subsection{Nueva economía política del tiempo informativo}

De acuerdo con Heidegger, el tiempo es el horizonte dentro del cual toda realidad adquiere sentido. En términos de Feuerbach, solamente quien adopta en todos los aspectos el punto de vista del espacio y del tiempo posee en la vida tacto y sentido práctico. El espacio y el tiempo son los primeros criterios para reformular toda práctica. En otras palabras, no hay comunicación posible sin mediación espacio temporal. Por lo mismo, una filosofía de la praxis comunicológica requiere una economía política del tiempo informativo y una ecología política de los ecosistemas de vida. El despliegue de las categorías espaciotemporales es parte del programa de toda teoría crítica en el análisis de la formación social real y concreta. Pues la localización permite adecuar los flujos de interacción según parámetros culturales concretos. Tres factores determinan en este sentido la cultura a este respecto: la mediación lingüística, el acontecer en su poder de ordenamiento y regulación social, y desde luego la mediación cronotópica, en tanto que organización locativa, de dirección y formación habitacional. Si hemos de concebir la Comunicación para el Buen Vivir como una política de la religancia, ello significa que es preciso pensar la Ecología de la Comunicación desde una visión compleja de la mediación en el ecosistema social-natural. La regulación de las asimetrías y concepción integral son inseparables de una vida plena o espléndida. Ello implica repensar la comunicación en su dimensión biológica, en el entorno y medio ambiente específico de la estructura del sentimiento, desde 
la experiencia mediadora del homo faber. La mediación social no es pensable sin analizar la articulación de los procesos de comunicación, socialización y producción del hábitat social. En particular, significa repensar la mediación al menos a tres niveles:

- La proxemia y el espacio físico de lo cotidiano o doméstico.

- La experiencia de lo vivido socialmente en toda interacción.

- La mediación cognitiva presente en toda representación a partir del lenguaje que interfiere entre objetos, sujetos y composición social.

Espacio, tiempo y lenguaje nos sitúan ante la necesidad de integrar en la Ecología de la Comunicación no sólo las relaciones sociales, como es habitual en la Teoría de la Comunicación, sino también las relaciones institucionales, sistémicas y medioambientales. Pero no hemos desarrollado al respecto suficiente reflexividad en ciencias sociales, y en Comunicología en particular, sobre la economía política del tiempo.

Es razonable pensar que el principio de integralidad, que el reconocimiento de la compleja trama del sentido de la vida en común pasa por una lógica distinta de la temporalidad informativa. Una Comunicación para el Buen Vivir, una Ecología Inteligente de la Comunicación exige una lógica temporal a contrapelo de la historia moderna, una suerte de slow information que haga posible la crítica del turbocapitalismo. La narrativa dominante de la economía de la información ha impulsado históricamente un crecimiento exponencial de los medios y flujos de señales. La idea de que cuanto más mejor es una concepción hoy hegemónica en la cultura informativa de los navegantes en la economía digital. Por ello, plantear la idea de Ecología de la Comunicación pasa por aprender el principio de decrecimiento y sobriedad implícito en la noción de Buen Vivir. Frente a esta velocidad de escape, la Comunicación para el Buen Vivir implica discutir reflexivamente el sentido de la economía de señales, atendiendo las necesidades vitales. Hasta hoy poco o nada hemos pensado estos y otros problemas asociados a la ley de hierro de la teoría matemática de la comunicación. Quizás no nos sirvan las fórmulas métricas para reivindicar una comunicación impulsora de los bienes relacionales. En cierto sentido, la Comunicología como Ciencia de lo Común, como Comunicación para el Buen Vivir, ha de ser pensada desde el plano de la inmanencia y la racionalidad de la narrativa del sentipensamiento. Desde este punto de vista, la ciencia aplicada de la Comunicología ha de ser repensada como arte y como técnica, y el trabajo de los mediadores como un oficio de artesanos. En términos de Sennett, se trataría de reivindicar la práctica concreta de la comunicación como "un laboratorio en el que investigar determinados sentimientos e ideas" (2013, p.13). Reivindicar una mayor reflexividad sobre el tiempo concreto y real, no en la lógica mecánica o secuencial del paradigma cartesiano, significa, en este sentido, una reivindicación de la praxis y los lugares comunes y concretos del hábitat y del ser en el mundo. Todo un reto para la investigación comunicacional en la era de la modernidad líquida.

\section{Conclusiones}

Las transformaciones contemporáneas de la globalización y el espíritu del Capitalismo Cognitivo sitúan un campo estratégico de lucha epistemológica en la comu- 
nicación, dada la centralidad que hoy adquiere el trabajo inmaterial y la práctica científica. En este horizonte, la tradición comunicacional de América Latina puede cumplir un papel estratégico, siempre y cuando se asuma la necesidad de un nuevo descentramiento que rompa con la tradición modernizadora heredera de la influencia occidental y en parte presente en la teoría de la dependencia y la propia ELACOM, a fin de reinterpretar, a partir de los debates decoloniales y postcoloniales, el sentido de una Epistemología del Sur para la Comunicología regional, reinstituyendo una agenda y mirada renovada de la práctica teórica local. El desfase entre el pensamiento y la política cultural, entre las luchas por la representación y emancipación de los pueblos indígenas y la investigación en comunicación constata en este punto la pertinencia de avanzar una línea de experimentación y trabajo teórico al respecto, que sólo ha de resolverse con mayor reflexividad, retomando la potencia crítica de la ELACOM, así como la potencia creativa de los movimientos indígenas. En este sentido, un primer reto para avanzar una Comunicología del Sur pasa por lograr el fortalecimiento de la investigación y de la comunidad de investigadores en América Latina desde la emancipación intelectual, en el sentido propuesto por Rancière, a saber:

"la emancipación como reapropiación de una relación consigo mismo perdida en un proceso de separación... Eso es lo que significa la palabra emancipación: la alteración de la frontera entre los que actúan y los que miran, entre individuos y miembros de un cuerpo colectivo... Una comunidad emancipada es una comunidad de narradores y de traductores" (2010:21-27).

Y una ciencia ingeniosa es un saber insurgente que captura lo común, la realidad vivencial desde una estrategia de descentramiento crítica contra las grandes narraciones sobre el cambio social. Esto significa definir una política científica de empoderamiento propio, de auto-reconocimiento, que revise los preceptos dominantes de la westernización de la teoría comunicacional. Ello pasa, de acuerdo a las tesis de Boaventura Sousa de Santos aplicado a nuestro campo, por Descolonizar la Comunicología, por medio de:

- La ruptura de los abismos epistémicos.

- El diálogo Sur-Sur.

- La politización de la investigación en comunicación.

- La discusión de la Economía Política de la Comunicación y del Conocimiento en la era del Capitalismo Cognitivo en forma de Arqueología del Saber-Poder Informativo en la modernidad otra de América Latina.

Si el campo y la academia están en un punto de inflexión como consecuencia de los cambios estructurales de la globalización capitalista, la Comunicología Latinoamericana puede renovar los paradigmas y modelos teóricos aprendiendo de la experiencia de los movimientos indígenas, tal y como está ocurriendo en otras disciplinas de las ciencias sociales, para proceder a una ruptura epistemológica de la colonialidad del saber comunicológico dominante. Ello requiere, al menos, tres condiciones para la práctica científica:

Construir formas institucionales más fuertes, coherentes y supranacionales, articulando redes de investigación potentes y transversales que contribuyan al 
fortalecimiento del campo autóctono. Necesitamos una "primavera académica" contra la privatización y monopolios privados del conocimiento que la globalización impone en el Capitalismo Cognitivo a favor de una mirada, teoría y práctica, o estilo de investigación angloamericano o euro-occidental que cercena los saberes condicionando las prácticas científicas autónomas y comunitarias en la región. En esta línea, si el capitalismo y las políticas de ciencia y tecnología separan, externalizan y disuelven las comunidades científicas que nos identifican, el reto es, justamente, tratar de religar, juntar, unir, conectar, compartir y reconstruir lo procomún latino para un pensamiento renovado, poscolonial y divergente, un pensamiento, en fin, de la disidencia y la diferencia reconocida y potencialmente emancipadora. Sólo así podremos acometer los retos de una Comunicología renovada y, lo que es más importante, sólo bajo esta condición tendremos la legitimidad que necesitamos atendiendo las demandas y necesidades de desarrollo de los pueblos y multitudes que, sólo indirectamente, nos interpelan porque no nos conocen ni nos esperan.

Favorecer la reflexividad científica y la metainvestigación para definir agendas, cuestionar el campo y permitir una mayor capacidad de auto-observación. El meta-análisis y la teorización siguen siendo pobres, insuficientes, y hoy con las políticas de $\mathrm{I}+\mathrm{D}$, crecientemente marginales, por el imperio de indicadores y sistemas de evaluación orientados tan pragmáticamente que lo urgente y necesario es desplazado por una miope visión de conjunto. Así, justo cuando más precisamos complejizar nuestra práctica científica y ganar potencia reflexiva para alterar el locus del campo, se observa una notoria carencia de perspectiva estratégica y producción epistémica en esta dirección. No obstantes, nombres como Raúl Fuentes han liderado esta voluntad de observación del campo o, más recientemente, la iniciativa, también en México, de Hacia una Comunicología Posible, pero son locales e insuficientes en su alcance, si insistimos en esta idea de historia conectada y de campo común.

Fomentar la naturaleza aplicada, productiva y creadora del campo de la comunicación. Una Comunicología del Sur implica un modelo de reproducción del conocimiento basado en el reconocimiento, la ecología de saberes, la justicia cognitiva global y una cultura académica anticolonial, anticapitalista y democrática de la producción del saber sobre la Comunicación en línea con muchas de las experiencias que están liderando los pueblos amerindios.

Ya sea desde la aculturación y enajenación, a las apropiaciones y sincretismos barrocos; así como de la dominación y exclusión ejercida por el patrón colonial y capitalista, a las políticas de resistencia y al diseño de agendas de liberación autonómica, el hecho irrefutable es que este antagonismo perenne ha permitido "configuraciones culturales"9 que hoy por hoy dan cuenta de una localización geopolítica y epistémica que se proyecta como un locus de enunciación fundamental para problematizar las diversas crisis que ha traído consigo la implementación y desarrollo del proyecto civilizatorio de la modernidad. En un tiempo de crisis civilizatoria, la Comunicología Latinoamericana ha de redefinir sus matrices epistémicas.

Con el concepto de "configuraciones culturales" Grimson (2011) se refiere a un "marco compartido por actores enfrentados o distintos, de articulaciones complejas de la heterogeneidad social" (201:172). O, en otras palabras, son los sistemas de identificación a través de los cuales los sujetos tornan coherente su relación entre sí mismos y sus lógicas de complementariedad o confrontación con los otros. 


\section{Bibliografía}

Bakhtin, M. (1981). Discourse in the novel. En M. Bakhtin, The dialogic imagination, four essays by M.M. Bakhtin (pp. 269-422). University of Texas Press.

Barranquero, A. y Sáez, Ch. (2014). Comunicación y Buen Vivir. La crítica descolonial y ecológica a la comunicación para el desarrollo y el cambio social. Palabra Clave, 18 (1), 41-82.

Beltrán, L., Herrera, K., Pinto, E., \& Torrico, E. (2008). La comunicación antes de Colón. Tipos y formas en Mesoamérica y los Andes. La Paz: Centro Interdisciplinario de Estudios de la Comunicación.

Beltrán. L., (1981). Adiós Aristóteles. La Comunicaicón Horizontal. Comunicación y Sociedad, 6, 5-35

Beltrão, L. (1971). Comunicación y folklore. São Paulo,: Contra-capa.

Beltrão, L. (2004). Folkcomunicação: Teoria e Metodologia. São Bernardo do Campo: UMESP.

Burke, P. (2010). Hibridismo cultural. Madrid: Akal.

Castro-Gómez, S. (2000). Ciencias sociales, violencia epistémica y el problema de la "invención del otro" En Lander, E. (Comp.) La colonialidad del saber. Eurocentrismo y Ciencias Sociales (pp. 145-161). Buenos Aires: CLACSO/CICCUS.

Catalán, C., \& Sunkel, G. (1991). La tematización de las comunicaciones en América Latina. Santiago de Chile: FLACSO.

Contreras, A. (2016). Aruskipasipxañanacasakipunirakispaw. In Sierra, F. \& Maldonado, C. (coords.) Comunicación, Decolonialidad y Buen Vivir (pp. 59 - 94). Quito: Ediciones CIESPAL.

De Sousa Santos, B. (2010a). Para descolonizar occidente: más allá del pensamiento abismal. Buenos Aires: CLACSO y Prometeo Libros.

De Sousa Santos, B. (2010b). Refundación del Estado en América Latiana: perspectivas desde una epistemología del sur (1a ed. ed.). Buenos Aires: Antropofagia.

Dussel, E. (1994). 1492. El encubrimiento del otro. Hacia el origen del «mito de la Modernidad». La Paz: Plural.

Dussel, E. (2002). Ética de la liberación en la edad de la globalización y la exclusión. España: Trotta.

Dussel, E. (2004). Sistema mundo y Transmodernidad. En Dube S, Banerjee, Ishita y Mignolo, Walter (eds.). Modernidades coloniales (pp. 201-226) México: El Colegio de México.

Dussel, E. (2011). Filosofía de la Liberación. México D.F: Fondo de Cultura Económica.

Echeverría, B. (1997). Las ilusiones de la modernidad. México: UNAM/EL Equilibrista.

Echeverría, B. (2011). Discurso Crítico y Modernidad. Ensayos escogidos. Bogotá: Ediciones Desde Abajo.

Fanon, F. (2001). Los condenados de la tierra. México D.F: Fondo de Cultura Económica.

Ferreira, L. (2000). Los códices y la ley de expresión precolombina. Diálogos de la Comunicación, 58, 80-93.

Gargurevich, J. (2002). La Comunicación imposible: información y comunicación en el Perú (siglo XVI). Lima: Universidad Mayor de San Marcos.

Grimson, A. (2011). Los límites de la cultura. Crítica de las teorías de la identidad. Buenos Aires: Siglo XXI.

Grosfoguel, R. (2016). Del «extractivismo económico» al «extractivismo epistémico» y «extractivismoontológico»: una forma destructiva de conocer, ser y estar en el mundo. Tabula Rasa, 24, 123 - 143. 
Habermas, J. (1993). El discurso filosófico de la modernidad. Madrid: Taurus.

Herrera, E., Sierra, F., Del Valle, C. (2016). Hacia una Epistemología del Sur. Decolonialidad del saber-poder informativo y nueva Comunicología Latinoamericana. Una lectura crítica de la mediación desde las culturas indígenas. Chasqui, 131, 77 - 105.

Kontopoulos, K. (1993). The Logics of Social Structure. London: Routledge.

Lander, E. (Comp.) (2000). La colonialidad del saber. Eurocentrismo y Ciencias Sociales. Buenos Aires: CLACSO/CICCUS.

Magallanes, C. y Ramos, J. (2016). Miradas Propias. Pueblos indígenas, comunicación y medios en la sociedad global. Quito: Ediciones CIESPAL

Maldonado, Claudio; Reyes, Carlos y del Valle, Carlos (2015): “Emergencia indígena, Comunicación-otra y Buen Vivir. Pensar la socio-praxis comunicativa de los pueblos indígenas", en Chasqui. Revista Latinoamericana de Comunicación, n ${ }^{\circ}$ 128, pp. 165-182.

Marques de Melo, J. y Gobbi, M.C. (Orgs.) (2003). Pensamento comunicacional latinoamericano. Da pesquisa-denuncia ao pragmatismo utópico. Sao Paulo: UMESP/UNESCO.

Martín-Barbero, J. (2010). De los medios a las mediaciones. Comunicación, cultura y hegemonía. Barcelona: Anthropos

Mignolo, W. (2003). Historias locales/diseños globales: colonialidad, conocimientos subalternos y pensamiento fronterizo. Madrid: Akal.

Moragas, M. (2011). Interpretar la comunicación. Estudios sobre medios en América y Europa. Barcelona: Gedisa.

Quijano, A. (1992). Colonialidad y modernidad/racionalidad. En Bonilla, H.(comp.) Los conquistados. 1492 y la población indígena de las Américas (pp. 437-448). Ecuador: Libri Mundi - Tercer Mundo.

Quijano, A. (2007). Colonialidad del poder y clasificación social. En: Castro-Gómez, S. y Grosfoguel, R. (eds.) El giro decolonial. Reflexiones para una diversidad epistémica más allá del capitalismo global (pp. 93-126) Bogotá: Iesco-Pensar-Siglo del Hombre Editores.

Quijano, A. y Wallerstein, I. (1992). “Americanity as a Concept, or the Americas in the Modern World-System”. ISSA, 134, 549-557.

Rancière, J. (2010). El espectador emancipado. Pontevedra: Ellago editores.

Restrepo, E. \& Rojas, A. A. (2010). Inflexión decolonial: fuentes, conceptos y cuestionamientos. Popayán, Colombia: Universidad del Cauca, Instituto Pensar, Universidad Javeriana.

Restrepo, P. y Valencia, J. (2016). Prácticas comunicativas en el Buen Vivir. In Restrepo, P.Valencia, J. y Maldonado, C. (coords.) Comunicadores y sociedades en movimiento: la revolución si está sucediendo (pp. 35-60). Quito, Ediciones CIESPAL.

Rivera Cusicanqui, S. (2006). Chhixinakax utxiwa. Una reflexión sobre prácticas y discursos descolonizadores. La Paz: U-PIEB- IFEA.

Rodríguez, L. (2005). Comunicação pública pré-colombiana em sociedades meso-americanas: fontes históricas para seu estudo entre Maias y Astecas. Revista brasilera de Ciências da Comunicação, XXVIII, 2, 43-68

Sierra, F. (2010). Comunicación, educación y desarrollo. Apuntes para una historia de la comunicación educativa. Sevilla: Comunicación Social Ediciones.

Tuhiwai, L. (2016). A descolonizar las metodologías Investigación y pueblos indígenas. Santiago de Chile: Ediciones LOM.

Vercellone, C. (2004). Las políticas de desarrollo en tiempos del capitalismo cognitivo. En Blondeau, O. et all. Capitalismo cognitivo, propiedad intelectual y creación colectiva (pp. 63-74). Madrid: Traficantes de Sueños.

Wallerstein, I. (2007). Universalismo Europeo: el discurso del poder. México: Siglo XXI. 
Walsh, C. (2005). Interculturalidad, conocimientos y decolonialidad. Signo y Pensamiento, XXIV, 46, 39-50. 